م.د/ نهى عبد العظيم عبد الحميا

المقدمة ومشكلة البحث:

لقد تطور الاهتمام العالمي بدراسة الثيخوخة بشكل واضح منذ النصف الثاني من القرن الماضي ، ولعل أهم العوامل التي دعت إلى الاهتمام بهذه المرحلة، هو تزايد أعداد المسنين في كافة دول العالم ، سواء النامية أم المتقدمة ، ومما لاثك فيه أن التغيرات التي يتعرض لها المسنون ، سواء الجسدية أو النفسية أو الاجتماعية تشكل ضغوطًا عليهم ، ويختلف المسنون في مدى شعورهم وإحساسهم بها وكيفية التعامل معها ، ويعزى ذللك إلى عدة متغيرات منها المساندة الاجتماعية، والاستعدادات الجسمية ، ووسائل وبرامج المواجهة. ويثير فؤاد أبو حطب وآمال صادق (^ . . r) أن الثيخوخة مرحلة مليئة بالتحديات والمهام الجديدة، والتي يجب مواجنها والتوافق معها ، والمسنون قد ينجحون أو يفشلون في مواجهة هذه التحديات، والمهام شأنهم في ذلك شأن صغار السن عند التعامل مع مهام الحياة الخاصة بمراحل نموهم $(001: 10)$.

وتزتبط مشاكل المسنين بالعديد من العوامل الاجتماعية ، والحالة الاقتصادية والتقاعد عن العمل

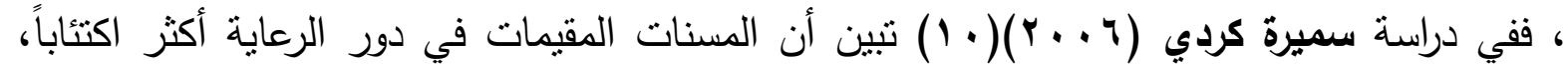
وشعوراً بالوحدة والعزلة من المسنات المقيمات مع أسرهن ، وأتضح من نتائج دراسة برينر Brener أن الحالة الاقتصادية والاجتماعية ترتبط إيجابياً بالسواء النفسي المقدر ذاتياً عند كبار (YV) ( . . V) السن ، ويعتبر الانسحاب الاجتماعي ، وفقدان الهدف ، وفقدان الأصدقاء ، وحجم الأسرة من العوامل المؤثرة على المسنين والمرتبطة بمشاكلهم ، وتعتبر التغيرات السلبية التي تطرأ على دينامية الروابط الأسرية أحد أهم العوامل المؤثرة على المسنين وتوافقهم النفسي والإجتماعى ، فذهاب الآباء المسنين إلى

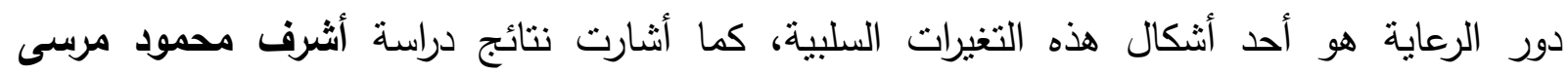

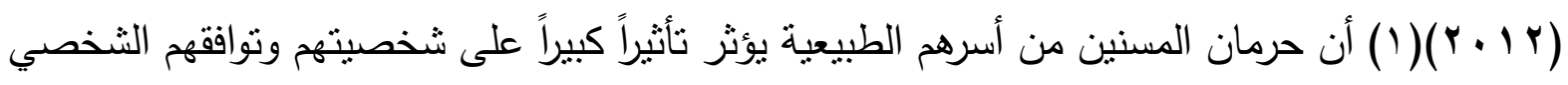
والاجتماعي وجودة الحياة.

* مدرس بقسم العوم التريوية والإجتماعية فى التربية الرياضية - كلية التربية الرياضية بنات - جامعة الزقازيق. 
ويعرف فون بونسدرف

والتدهور التدريجي في قدرة الفرد على التكيف مع التغيرات التي يواجهها وتفرضها ظروف الحياة". $(\wedge,:$ : (1)

وتعتبر المساندة الاجتماعية Social support من المفاهيم التى أختلف الباحثون فى طريقة تتاولها تبعـا لتوجهاتهم النظريـة ، فقد تتـاول علمـاء الاجتمـاع هذا المفهوم فى إطار تتـاولهم للعلاقات الاجتماعية ، حيث صاغوا مصطلح شبكة العلاقات الاجتماعية Social Network، الذى يعتبر البداية الحقيقيـة لظهور مصطلح المسـاندة الاجتماعيـة ، ويطلاق عليـه البعض مصطلح المـوارد أو الإمكانات

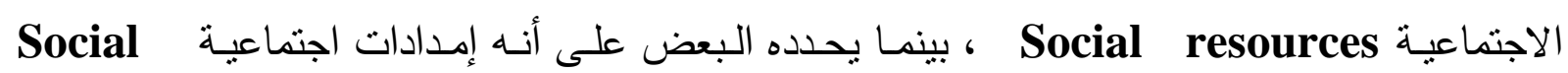

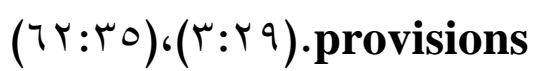
وتعرف بشرى إسماعيل (ع ا ب r) المساندة الاجتماعية بأنها" جميع الإمدادات التي يقدمها الآخرون للفرد لمساعدته على مواجهة الضغوط ، فالمساندة الاجتماعية تتقل الإحساس بأن الفرد ليس لوحده في مواجهة الضغوط أو التهديد "(:0با ())، ويذكر محمد محروس الثناوى ومحمد السيد عبد الرحمن (10 ب ب) أنه يقصد بالسند الاجتماعي تللك العلاقات القائمة بين الفرد وآخرين، والتي بدركها على أنها يمكن أن تعضده عندما يحتاج إليها ، أو أنها السند العاطفي الذي يستمده الفرد من آخر بالقدر الذي يساعده على التفاعل الايجابي مع الأحداث الضاغطة ، ومع متطلبات البيئة التي يعيش فيها ، بالإضافة لذلك فإن المساندة الاجتماعية هي أن يشعر الفرد بأن هناك من بهنم به اهنماماً عميقاً ، ويقدره أو أن يشعر الفرد باندماجه الثديد مع الآخرين ، وتلعب المساندة الاجتماعية دوراً هاماً في خفض بـ لهن المعاناة الناتجة عن شدة الأحداث.(9 (1) ويشير ليبور Lepore (ع 99 ( ) أن المسـاندة الاجتماعيـة هـى الإمكانـات الاجتماعيـة المتاحة

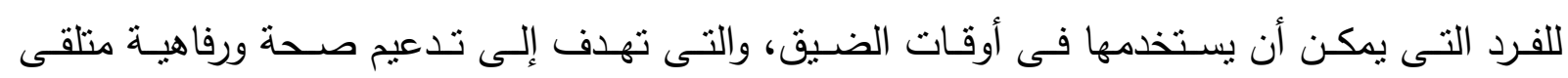

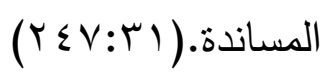

وللمسـاندة الاجتماعيـة وظائف متعددة فهى تسـهم فى توفير الراحة النفسية ، حيث أن التفاعل الاجتماعى المساند يولد درجة من المشاعر الإيجابية التى تحقق الصحة النفسية، وتخفف المعاناة من بعض الاضطرابات النفسية كالقلق، والاكتئاب ، والوحدة النفسية ، كما أن لها وظيفة نمائية عندما يكون لدى الفرد شبكة من العلاقات الاجتماعيـة الحميمـة التى تشـاعده على تحقيق التوافق الإيجابى ، ولها 
وظيفة وقائية فى مساعدة الفرد على مواجهة الأحداث الخارجية التى بدركها على أنها شاقة وتمثل ضغوط

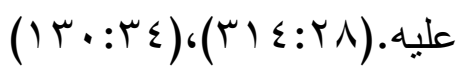

ويذكر أمطانيوس ميخائيل ( • ( ؟ ) أن الإحساس بالرضا عن الحياة يعتبر أحد المؤشرات التي تبين مدى تمتع الفرد بصحة نفسية جيدة ، والثعور بالسعادة في الحياة ، كما أن الرضا عن الحياة برتبط إيجابياً بتقدير الفرد لذاته ، وأن تقدير الفرد لذاته يعد أحد أهم العوامل المسئولة عن إحساس الفرد بالرضا عن الحياة ، كما أن الإحساس بعدم الرضا عن الحياة ذو تأثثر على شخصية الفرد وتكيفه، وعلاقاته داخل المجال الاجتماعي الذي يعيش فيه.(ب: . . ( )

وتتير سناء سليمان ( • ب أن السعادة لها أهميتها بوصفها الهدف الإنساني الأسمى ، كما أن أسبابها تبدو واحدة في مختلف أنحاء العالم ، وعلى اختلاف التقافات فإن العناصر المحددة والأساسية التي تسهم في خلق السعادة تبدو عامة.(1 (10با (1) وتعد السعادة من المشاعر الراقية السامية ، وهي انفعال وجداني إيجابي مازال الإنسان ينشد الوصول إليه ، وقد تحيط بنا ، ولكن قد يكون الوصول إليها باعتبارها غاية من غايات الإنسان الأساسية

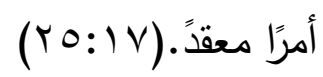

ويعرف فهمى على ( • ( + r) التوجه نحو الحياة بأنها "سمة في الثخصية توسم بأنها روئة ذاتية إيجابية واستعداد كامن لاى الفرد - غير محدودة بشروط معينة - يمكنه من توقع البشر، وإدراك كل ما هو إيجابي من أمور الحياة الجيدة وغير الجيدة ، وذلك بالنسبة للحاضر الحالي والمستقبل".(ع (1007) ويتفق كل sن : كمال درويش ومحمد الحماحمى (99VI))، تهانى عبد السلام (1 ( . ب) ، محمد الحماحمى (؟ . . Y) على أن ممارسة الأنشطة الترويحية تعتبر ضمن نسيج النظم الإجتماعية التى يتألف منها المجتمع، وبدأ الإهتمام بها كأحد مظاهر السلوك الحضارى للفرد لما لها من دور هام فى تحقيق التوازن بين العمل والراحة ، وكذللك لإسهاماتها فى تحقيق السعادة للإنسان ، كما تعد ممارسة الأنشطة الترويحية مدخلاً ملائماً لحل كثير من المشكلات التى قد تواجه الفرد فى الحياة المعاصرة ، وعاملاً مساهماً فى عمليات النمو المتكامل والمتوازن للشخصية ، وإستقرار المجتمع ، وإثراء الحياة المتوافقة مع متغيرات العصر الحديث. $($ (Yフ 
وتتير أمل عبد العزيز وعبد الرحيم بخيت (9999 19 ) أن التقدم فى العمر بصاحبه إنخفاض فى

التوافق النفسى والاجتمـاعى ، والثـعور بـالقلق وإنخفاض مفهوم الذات لديهم ، فتقل قدرة المسن على . استغلال امكاناته الجسمية والعقلية والنفسية فى مواجهة ضغوط الحياة.(ع : Y ( )

وتشير الباحثة إلى أن فئة المسنين هي أقل الفئات العمرية حظاً في المجتمع حيث لم تحظى هذه الفئة بالاهتمام اللازم ، وإن حظيت ببعض الاهتمام فأنه يعد هامشياً ، وغير كاف مقارنة بما تحظى بـه الفئات العمرية الأخرى.

ومن خـل قيام الباحثة بالعديد من الزيارات الميدانية لبعض دور الرعايـة الإجتماعية للمسنين بمحافظة الثرقية ، وحوارها معهم لاحظت أن عدداً غير قليل منهم تبدو عليه فقدان العلاقات الاجتماعية ، والعديد من الاهتمامات والنشاطات وزيادة الاعتمادية ، وعدم التقة بالذات، والثعور بالوحدة والعزلة الإجتماعية ، وترجع الباحثة السبب فى ذلك إلى أن إحالة الفرد لسن المعاش لها تأثير على متغيري التوافق والرضا عن الحياة لاعى المسنين ، حيث يشعر المسن بالحزن واليأس، وضعف نوافقه الشخصي والاجتماعي ، وذلك نظرا لعدم استمرار إثباع دوافع العمل لديه إضـافة إلى زيادة وقت الفراغ ، وشعوره بعدم اهتمام المجتمع به مما يعوق توافقه النفسي والاجتماعي ، وعدم القدرة على مواجهة المشاكل مما يؤثز ذلك على مستوى السعادة والصحة النفسية لديهم ، وتوجههم نحو الحياة ، وبالتالي فإن الثـور بالسعادة يؤدي إلى شعور الفرد بالتفاؤل والتوجه الإيجابي نحو الحياة مهما كانت المتاعب والضغوط التي

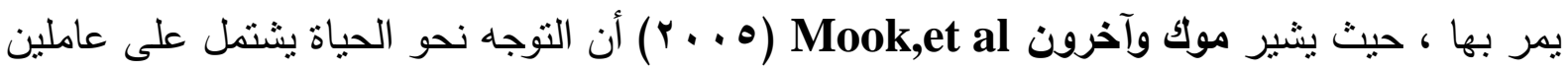
إحداهما التفاؤل ، والثاني التشاؤم ، كما أن الثعور بالانفعالات الإيجابية مهم ليس لأنه ممتع في حد ذاته ، ولكن لأنه بسبب تعاملا أفضل مع الحياة ، فتتمية الانفعالات الإيجابية أكثر في حياتتا سيبني الصداقات والحب والصحة الجسمية بصورة أفضل، ويحقق إنجازًا أكبر .(YVV:T) وبالرغم من تتاول العديد من الدراسـات المرجعية للبرامج الترويحية لمختلف الفئات العمرية مثل

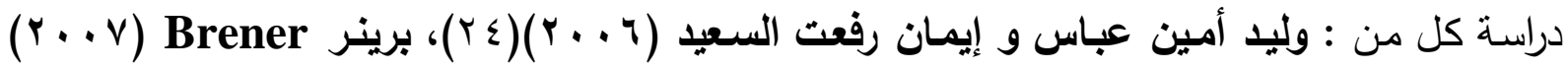

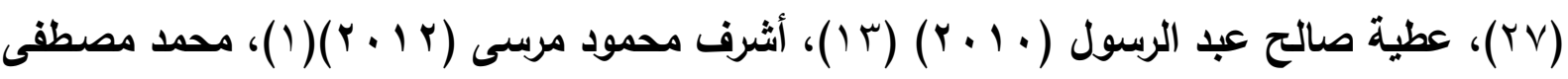

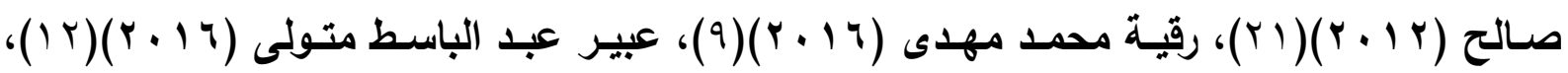

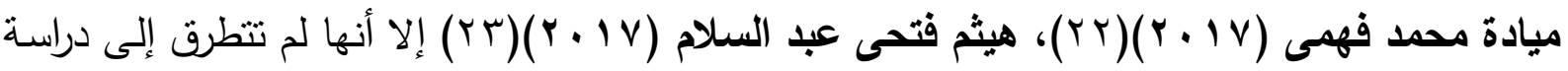
تأثثر ممارسـة الأنشطة الترويحيـة الرياضية على المساندة الإجتماعيـة والثـعور بالسـعادة والتوجـه نحو الحياة لدى كبار السن ، بالإضافة إلى ندرة البحوث التجريبية التي تتاولت المساندة الإجتماعية والثـور بالسعادة والتوجه نحو الحياة للى المسنين ، ومن هذا المنطلق العلمى رأت الباحثة بناء برنامج ثرويحى 
رياضى مقترح والتعرف على تأثيره على المساندة الإجتماعية والثعور بالسعادة والتوجه نحو الحياة لدى كبار السن من (07- • ع) سنة بدور الرعاية الإجتماعية بمحافظة الثرقية. أهداف البحث : n

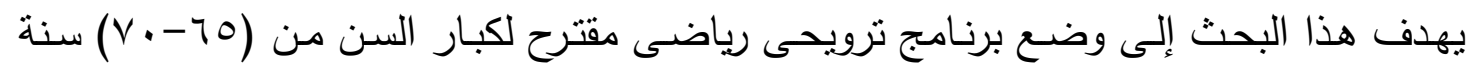

بدور الرعاية الإجتماعية يتضمن مجموعة من الأنشطة الترويحية الرياضية ومعرفة تأثير ذلك على :

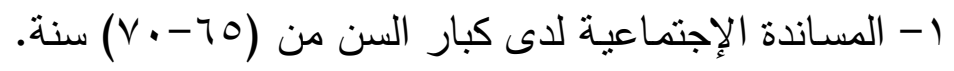
ץ- الثعور بالسعادة والتوجه نحو الحياة لدى كبار السن من (0 >- •) سنة.

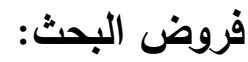

ا- توجد فروق دالة إحصائياً بين متوسطى القياسين القبلى والبعدى لأفراد عينة البحث الأساسية فى المساندة الإجتماعية والثعور بالسعادة والتوجه نحو الحياة لصالح القياس البعدى.

ץ- توجد نسب تحسن للقياس البعدى عن القبلى لأفراد عينـة البحث الأساسية فى المساندة الإجتماعيـة والشعور بالسعادة والتوجه نحو الحياة.

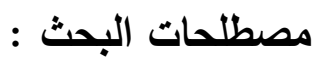

\section{الترويح Recreation:}

هو" النشـاط البناء الممارس في وقت الفراغ بالاختيـار الحر دون توقع أي عائد مـادي بغرض الكسب، بهدف اكتسـاب الخبرات العقلية والاجتماعية والبدنية والصـحية ولإحداث التوازن والتكامل لدي الأفراد حتى يتم إعدادهم لحياتهم العامة".(1 ( : ؟7)

\section{المساندة الاجتماعية Social support}

هى " وجود عدد كافى من الأشخاص فى حياة الفرد يمكنه الرجوع إليهم عند الحاجة ، وأن يكون لدى هذا الفرد درجة من الرضا عن هذه المساندة المتاحة له ".(9 (10:1 (1)

: Happiness السعادة

هى " لا تعني فقط غياب المشاعر الاكتئابية، ولكنها تعني أيضًا وجود عدد من الحالات

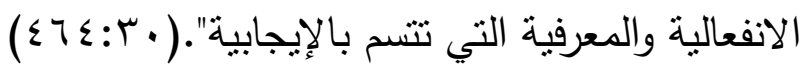

\section{التوجه نحو الحياة Life Orientation Among}


هو" اتجاه من جانب فرد ما نحو الحياة أو نحو أحداث معينة، يمبل أحيانًا إلى حد مفرط للعيش على الأمل، أو نحو التركيز على الناحية المشرقة من الحياة أو الأحداث أو الجانب المفعم بالأمل

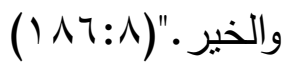

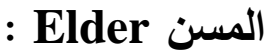

هو" الثخص الذي تجاوز الستين من عمره ويزداد اعتماده على غيره بازدياد نراجع وظائفه الجسدية والنفسية والاجتماعية، ويختلف هذا تبعًا لشخصية المسن والمعايير الاجتماعية والثقافية السائدة في المجتمع".(تعريف إجرائى) الاسرات المرجعية : n

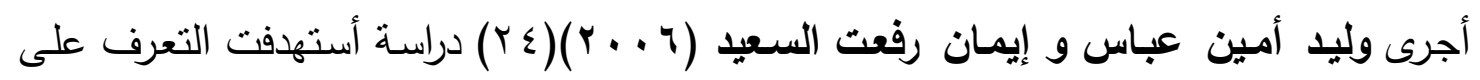
تأثير برنامج نرويحي رياضي مفترح على الحالة النفسية والاجتماعية لكبار السن فوق سن (07) سنة ، وأستخدم الباحثان المنهج التجربيـى على عينـة عمديـة قوامها ( • (ب) رجل مُسن من المترددين على أحد الأندية المعنية بكبار السن بمحافظة الجيزة ، ومن أهم النتائج : فاعلية البرنامج الترويحي الرياضي فى تحسين الحالة النفسية والاجتماعية لكبار السن.

وقام برينر الرياضية على الأجهزة الحيوبـة والنفسية لدى المسنين ، وأستخدم الباحث المنهج التجربيى على عينة قوامها (9 §) رجـاً ، ومن أهم النتائج : تؤثز ممارسـة الأنشطة الرياضية تأثيراً إيجابياً على السمات الثخصية الإرادية وانخفاض مستوى القلق لدى المسنين.

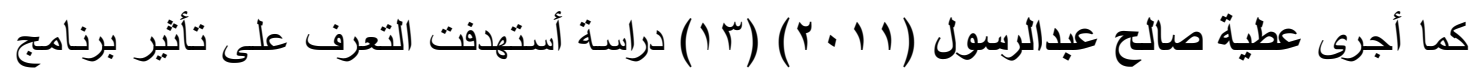
ترويحي رياضي مقترح على تتمية بعض عناصر اللياقة البدنية والخصائص الإجتماعية للتناميذ المعاقين سمعياً بشعبية بنغازى ، وأستخدم الباحث المنهج التجريبى ، وأثتنلت عينة البحث على عدد ( • ع) تلميذاً بالمرحلة الإعدادية بمركز الصم وضعاف السمع ، ومن أهم النتائج : يؤثز البرنامج الترويحي الرياضي ، تأثثراً إيجابياً على الخصائص الإجتماعية للتلاميذ المعاقين سمعياً. وأجرى أشرف محمود مرسى (Y l • r) ( ) دراسة أستهدفت التعرف على تأثنير برنامج ترويحى رياضـى مـائى على بعض المتغيـرات النفسية لدى كبار السـن ، وأسـتخدم الباحث المنهج التجريبى ، وتكونت عينة البحث من عدد (•0) رجل مُسن من المترددين على نادى الثبان بمحافظة بنى سويف تتراوح أعمارهم مـا بين (17 - 7 7) سـنة ، ومـن أهم النتائج : البرنـامج الترويحى الرياضسى لـه تأثثر 
إيجابى دال إحصائياً على المتغيرات النفسية (القلق - التوافق النفسى - مفهوم الذات الجسمية) لدى كبار السن.

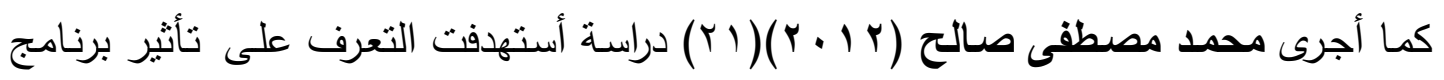
ترويحي رياضـى على مستوى مهارات التفاعل الإجتمـاعى لدى الأطفال التوحديين ، وأستخدم الباحث المنهج التجريبى على عينة قوامها (0) أطفال ذكور توحديين ، ومن أهم النتائج : يؤثز البرنامج الترويحي الرياضى تأثيراً إيجابياً على مستوى مهارات التفاعل الإجتماعى لدى الأطفال التوحديين.

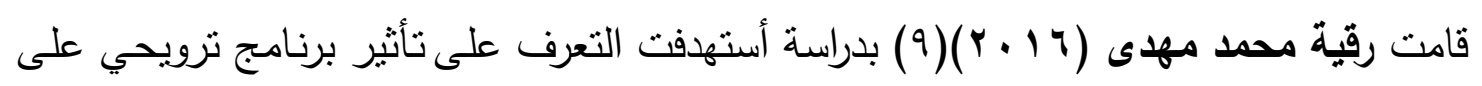
تتميـة المهارات الإجتماعيـة للصـم والبكم بمحافظـة المنوفيـة، وأسـتخدمت الباحثـة المـنهج التجريبـى ، وأثنملت عينة البحث على عدد (·r) تلميذة بمعه الأمل للصم وضعاف السمع تحت (ع ()سنة ، ومن أهم النتائج : تحسنت المهارات الإجتماعية للصم والبكم نتيجة لممارسة البرنامج الترويحي.

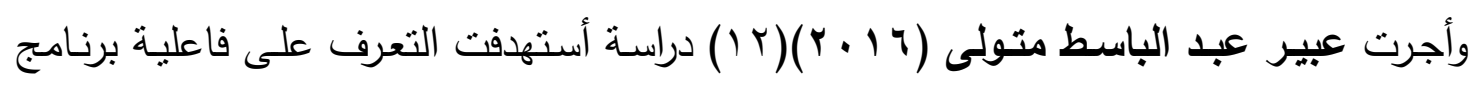
ترويحي باستخدام الألعاب الصغيرة والتمهيدية على تتمية بعض المهارات الأساسية والتفاعل الإجتماعى للناشئين فى كرة السـلة ، وأستخدمت الباحثة المنهج التجريبى ، وتكونت عينة البحث من عدد ( • (ب)

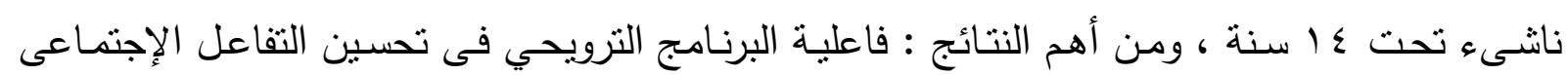
لناشئي كرة السلة.

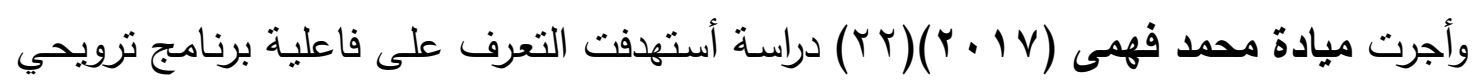
رياضـي على جودة الحياة للسيدات كبار السن ، وأستخدمت الباحثنة المنهج التجريبى ، وأشتملت عينة البحث على عدد (T ( ) سيدة ، ومن أهم النتائج : يؤثز البرنامج الترويحي الرياضي تأثنراً إيجابياً دال إحصائياً عند مستوى (0 . . •) على جودة الحياة للسيدات كبار السن.

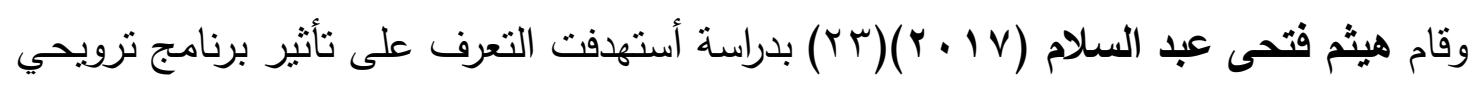
مائى على خفض السلوك النمطى وتتمية التفاعل الإجتماعى لدى أطفال التوحد، وأستخدم الباحث المنهج التجريبى ، وتكونت عينـة البحث من عدد ( • () أطفال من المتوحدين ، ومن أهم النتائج : البرنـامج الترويحي المائى له تأثير إيجابى على تتمية التفاعل الإجتماعى لدى أطفال التوحد. 


$$
\text { منهرج البحث: }
$$

أستخدمت الباحثة المنهج التجريبى نظراً لملائمته لطبيعة البحث، وتم الإستعانة بالتصميم

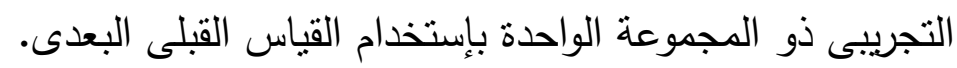

\section{مجتمع وعينة البحث:}

يتضـمن مجتمـع البحث كبار السـن المقيمين بـدار الثـوبك للمسنين ، وبدار مستثفى السـلام

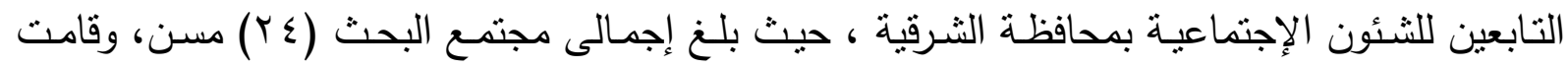

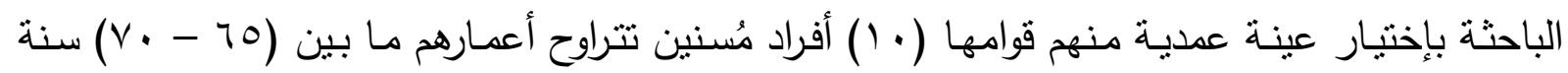

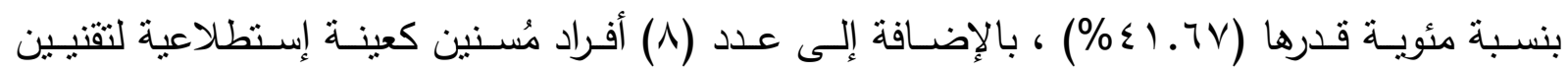

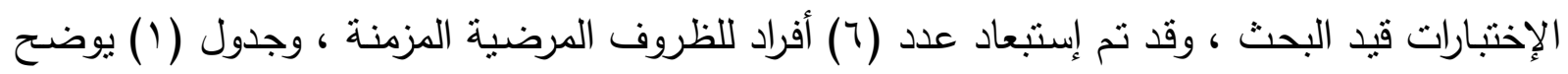
تصنيف عينة البحث :

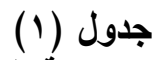

\begin{tabular}{|c|c|c|c|c|}
\hline \multirow{2}{*}{ النسبة المئوية } & \multirow{2}{*}{ مجموع العينة } & \multicolumn{2}{|c|}{ المستبعدون } & \multirow{2}{*}{ مجتمع البحث } \\
\hline & & المستبعدين & عينة البحث الإستطلاعية & \\
\hline$\% \leq 1.7 V$ & 1. & 7 & $\Lambda$ & $Y \leq$ \\
\hline
\end{tabular}

تصنيف عينة البحث (1) شروط إختيار عينة البحث:

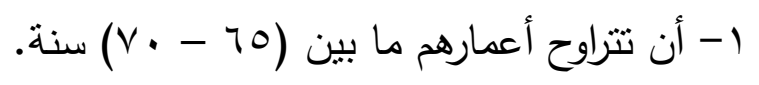

r- الرغبة فى المشاركة فى البرنامج بعد توضيح فوائده وإجراءاته.

r- إستبعاد المُسن الذى لا تسمح حالته البدنية والصحية بممارسة الأنشطة الترويحية الرياضية.

إعتدالية توزيع أفراد عينة البحث:

قامت الباحثة بحساب إعتدالية نوزيع أفراد عينة البحث من حيث متغيرات النمو (السن - الطول

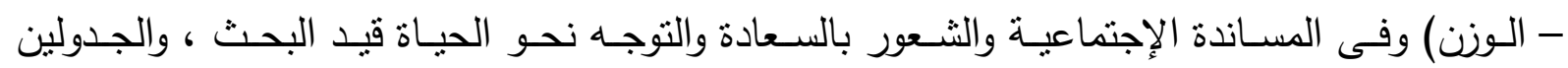

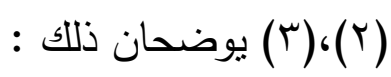


$-\leqslant Y \cdot-$

تـأتيـر برنامج ترويحى ريـاضى على المسـاندة الإجتمـاعيـة و الثُعور بالسعادة والتوجه نحو الحياة لاى كبار السن

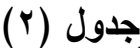

إعتدالية توزيع أفراد عينة البحث فى السن

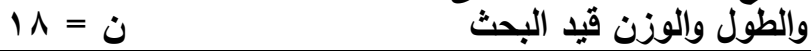

\begin{tabular}{|c|c|c|c|c|c|}
\hline معامل الإلتواء & الوسيط & الإنعبارى & المستوبط & القياس & المتغيرات \\
\hline $1.1 \mathrm{r}$ & 77.7. & Y.\&I & 78.0. & السنة: & السن \\
\hline 1.97 & ivi... & 0.14 & ivr.AT & سم & 'الطول' \\
\hline..$\wedge r$ & $\wedge \varepsilon .0$. & $9 . r r$ & 19.10 & كجم & "الوزن \\
\hline
\end{tabular}

يتضح دن جدول (r) أن جميع قيم معاملات الإلنواء لمعدلات النمو (السن ، الطول ، الوزن )،

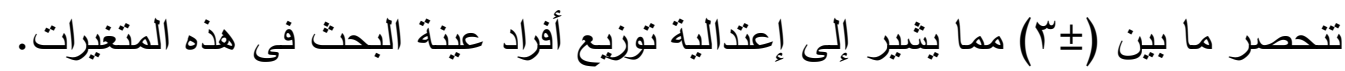

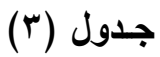

إعتدالية توزيع أفراد عينة البحث في المساندة الإجتماعية

والثعور بالسعادة والتوجه نحو الحياة قيد البحث

\begin{tabular}{|c|c|c|c|c|c|}
\hline معامل الإلتواء & الوسيط & الإنحراف & المتوسط الحسبى & القياس & المتغيراد \\
\hline $.7 \leqslant$ & $97 . .$. & $V . . \varepsilon$ & 98.0. & درجة & المساندة الإجتماعية \\
\hline..$\wedge V$ & $r \varepsilon \ldots$ & 7.01 & $r 0.19$ & درجة & الشعور بالسعادة \\
\hline. .11 & 19... & 0.11 & TV.YY & درجة & التوجه نحو الحياة \\
\hline
\end{tabular}

يتضـح مـن جدول (r) أن جميع قيم معاملات الإلتواء للمسـاندة الإجنماعيـة والثـعور بالسـعادة

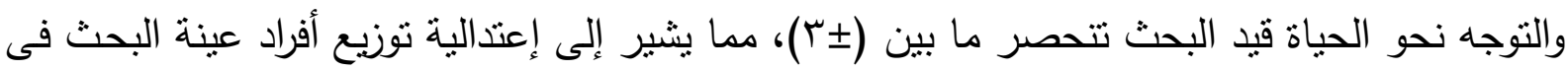

هذه المتغيرات.

أدوات جمع البيانات : n

قامـت الباحثـة بـالإطلاع على العديـد مـن المراجـع العلميـة المتخصصــة والدراسـات المرجعيـة

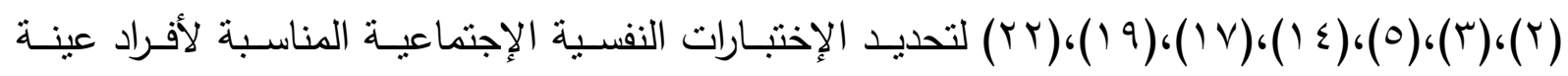
البحث هوقد أسفر ذلك عن الإختبارات التالية :

أولاًا : مقياس السعادة والتوجه نحو الحياة : إعداد الباحثة

لدراسة مستوى السعادة وعلاقتها بالتوجه نحو الحياة لدى كبار السن تم تصميم مقياس خاص لهذا الغرض ، وهذا المقياس يتضمن بعدين رئيسيين (الثعور بالسعادة لدى المسنين - التوجه نحو الحياة لدى المسنين)، وإجمالى عدد عبارات المقياس (· (r) عبارة. وتتم الإجابة على عبارات المقياس في ضوء الاستجابات التالية: 


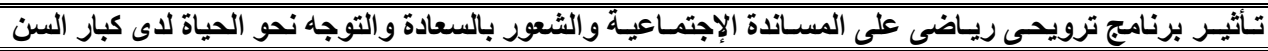

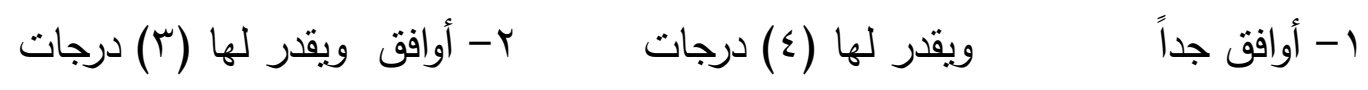

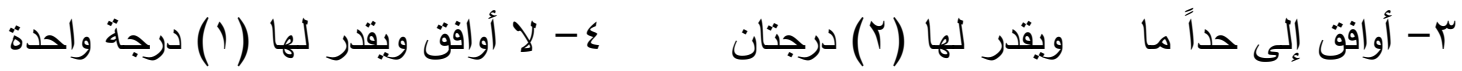

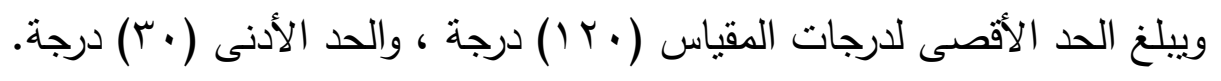

وقد تم تحديد الأبعاد والعبارات للمقياس من خلال إطلاع الباحثة على العديد من مقاييس السعادة

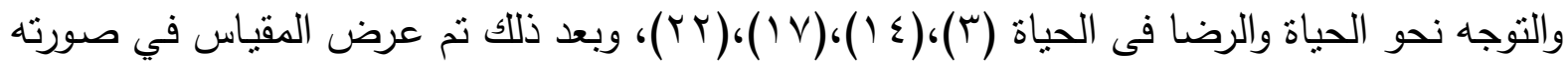
الأولية عدد (0ب) عبارة على مجموعة من الخبراء فى علم الإجتماع الرياضي والقياس ملحق (1) فتم حذف عدد (0) عبارات ، وبذلك أصبحت عدد عبارات المقياس فى صورته النهائية (·r) عبارة موضحة بملحق (r) ، وجدول (ع) يوضح ذلك.

جدول (؛)

أرقام العبارات النهائية لمقياس السعادة والتوجه نحو الحياة

\begin{tabular}{|c|c|c|c|}
\hline 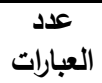 & أرقام العبارات النهائية & أبعاد المقياس & r \\
\hline 10 & 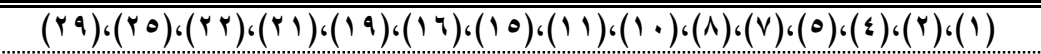 & الشعور بالسعادة & 1 \\
\hline 10 & 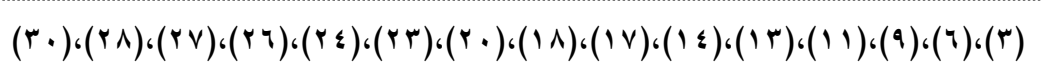 & التوجه نحوة & r \\
\hline$r$. & - & جمالى العبارات & \\
\hline
\end{tabular}

يتضح من جدول (ع) أن عدد عبارات المقياس النهائية والتى تم الإتفاق عليها هى (·r) عبارة ، حيث تم إختيار العبارة التى لا تقل نسبة إتفاق الخبراء عليها عن ( •^\%). المعاملات العلمية (الصدق - الثبات) لمقياس السعادة والتوجه نحو الحياة:

أ - معامل الصدق

أستخدمت الباحثة صدق الإتسـاق الداخلى حيث تم تطبيق مقياس السعادة والتوجهـ نحو الحياة على عينة قوامها (^) أفراد من خارج العينة الأساسية للبحث، وتم حساب معامل الارتباط بين درجة كل عبارة من عبارات المقياس والدرجة الكليـة للمقياس ، وجدول (0) يوضـح ذلك ، كما تم حسـاب معامل الارتباط بين درجة كل عبارة والدرجة الكلية للبعد الذى تمثله وجدول (T) يوضح ذلك ، وأيضاً تم حساب معامل الارتباط بين الدرجة الكلية لكل بعد من أبعاد مقياس السعادة والتوجه نحو الحياة والدرجة الكلية للمقياس ، وجدول (V) يوضح ذلك.

مجلة بحوث التربية الثاملة ـ كلية التربية الرياضية للبنات - جامعة الزقازيق ـ المجلد الأول ـ للنصف الأول للأبحاث العلمية ـ 1 I ب م 
- EY _

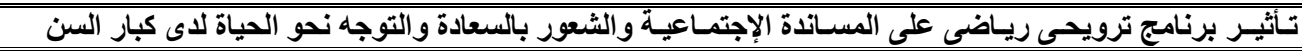

جدول (0)

معامل الارتباط بين درجة كل عبارة من عبارات مقياس

السعادة والتوجه نحو الحياة والارجة الكلية له لهارئ

\begin{tabular}{|c|c|c|c|c|c|c|c|}
\hline قيمة "ر" & رقم العبارة & قيمة "ر" & رقم العبارة & قيمة "ر" & رقم العبارة & قيمة "ر" & رقم العبارة \\
\hline. .190 & ro & $\cdot . \wedge \cdot 1$ & IV &. .1997 & 9 &. .111 & 7 \\
\hline . VAv & pq & .var & 11 &. .111 & 1. & .V9 & r \\
\hline - VAr & rV & $\because \vee \wedge \wedge$ & 19 & $\cdot . \vee \vee r$ & 11 & $\cdot . \Lambda \cdot r$ & $r$ \\
\hline$\cdot . \Lambda \cdot \varepsilon$ & үर &.$V 90$ & $r$. & .099 & Ir & . VAᄉ & $\varepsilon$ \\
\hline. .117 & pq & $\cdot . \Lambda \cdot r$ & ri &. $.11 \%$ & 15 &.$v 90^{\circ}$ & 0 \\
\hline \multirow[t]{3}{*}{$\cdot . \wedge \cdot r$} & $r$. & $\cdot . \wedge 1 V$ & $r r$ & $\cdot . \wedge$ & $1 \leq$ & .1991 & 7 \\
\hline & & $\cdot \wedge \ldots$ & $r r$ & -.V99 & 10 & $. .11 \leq$ & v \\
\hline & & . Vqr & $r \varepsilon$ & $\because \vee \wedge \bullet$ & 17 & $\cdot . \Lambda \cdot r$ & $\Lambda$ \\
\hline
\end{tabular}

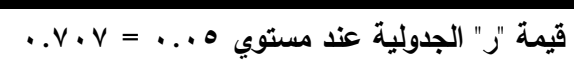

يتضح من جدول (0) وجود إرتباط دال إحصائياً عند مستوى ه . .. بين درجة كل عبارة من عبارات مقياس السعادة والتوجه نحو الحياة والدرجة الكلية للمقياس ، مما بشير إلى صدق الإتساق

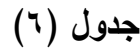

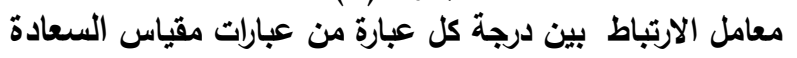

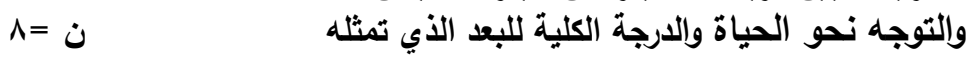

\begin{tabular}{|c|c|c|c|c|c|c|c|}
\hline \multicolumn{4}{|c|}{ التوجه نحو الحياة } & \multicolumn{4}{|c|}{ الشعور بالسعادة } \\
\hline قَيمهُ "ر" & رقم العبارة & قُيمة "ر" & رقم العبارة & قُيمة "ر" & رقم العبارة & قُيمة "ر" & رقمم العبارة \\
\hline..$\vee \wedge r$ & $r \cdot$ &..$\wedge 1 Y$ & $r$ &. .297 & 10 & . .Var & 1 \\
\hline. .291 & $r r$ & $\cdot . \Lambda \cdot r$ & 7 &. .291 & 17 & $\cdot . \Lambda \cdot 1$ & r \\
\hline$\because \vee \vee \vee q$ & $r \varepsilon$ &..$\vee 99$ & 9 & $\because \vee \wedge \diamond$ & 19 &. $.11 \%$ & $\varepsilon$ \\
\hline$\because \vee \vee 4$ & rq & $\because \vee \vee 0$ & 11 & $\because \vee \vee \vee$ & pi &.$\vee 190$ & $\bullet$ \\
\hline$\cdot . \wedge \cdot 1$ & rv &. .291 & ir & $\cdot . \Lambda \cdot r$ & $r r$ &.$\vee \vee \wedge \wedge$ & v \\
\hline. .117 & үᄉ &..$\vee V V$ & $1 \leqslant$ &. $.11 \varepsilon$ & ro & $. \vee V 9 \leq$ & $\Lambda$ \\
\hline \multirow[t]{2}{*}{$\because \vee \wedge 9$} & $r$. &..$\wedge 1 Y$ & iv & $\cdot . \Lambda \ldots$ & rq & $\cdot . \Lambda \cdot r$ & 1. \\
\hline & &..$\vee \wedge 4$ & 11 & & &. .111 & ir \\
\hline
\end{tabular}

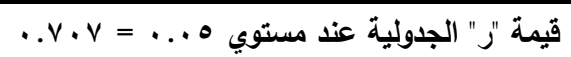

يتضح من جدول (7) وجود إرتباط دال إحصائياً عند مستوى ه . . . بين درجة كل عبارة من عبارات مقياس السعادة والتوجه نحو الحياة والدرجة الكلية للبعد الذي تمثله، مما يثير إلى صدق الإتساق الداخلي للمقياس.

(v) (ل)

معامل الارتباط بين الدرجة الكلية لكل بعد من أبعاد مقياس

\begin{tabular}{|c|c|c|}
\hline ققيمة "ر" & الأبعاد & A \\
\hline "*..Aro & الثعور بالسعادة & $T$ \\
\hline$* \cdot . \wedge \cdot r$ & التوجه نحو الحياة & $\xi$ \\
\hline
\end{tabular}

قيمة "ر" الجدولية عند مستوي ه... = v v. v.

مجلة بحوث التربية الثناملة - كلية التربية الرياضية للبنات - جامعة الزقازيق - المجلد الأول - للنصف الأول للابحاث العلمية ـ 1 ا ب rم 
يتضح من جدول (V) وجود إرتباط دال إحصائياً عند مستوى ه . . • بين الدرجة الكلية لكل بعد

من أبعاد مقياس السعادة والتوجه نحو الحياة والدرجة الكلية للمقياس.

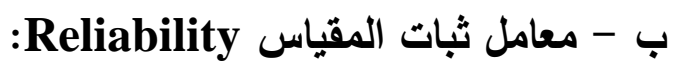

لحساب معامل الثبات تم إستخدام طريقة تطبيق الإختبار ثم إعادته مرة أخرى، وذلك عن طريق

تطبيق مقياس السعادة والتوجه نحو الحياة على العينة الاستطلاعية وعددها (^) أفراد من مجتمع البحث

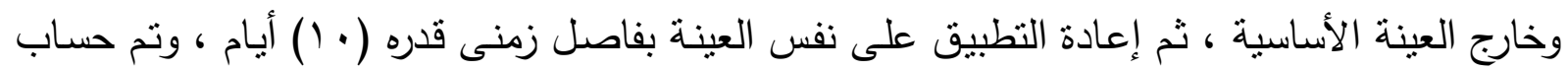
معامل الارتباط بين نتائج التطبيقين الأول والثانى ، وجدول (^) يوضح ذلك.

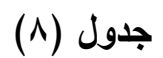

معامل الثبات لمقياس السعادة والتوجه نحو الحياة قيد البحث

\begin{tabular}{|c|c|c|c|c|c|c|}
\hline \multirow{2}{*}{ قيمة "ر" } & \multicolumn{2}{|c|}{ التطبيق الثاني } & \multicolumn{2}{|c|}{ التطبيت الأول } & \multirow{2}{*}{ وحدة القياس } & \multirow{2}{*}{ أبعاد المقياس } \\
\hline & $\varepsilon$ & 5 & $\varepsilon$ & م & & \\
\hline$* . . \wedge \mid r$ & $\varepsilon .11$ & ro.0. & 8.71 & $r \varepsilon . \Lambda$. & درجة & الشعور بالسعادة \\
\hline$* . .891$ & $r .90$ & $r q . V$. & $\varepsilon . Y T$ & ro.o. & لدرجة & التوجه نحو الحياة \\
\hline
\end{tabular}

يتضح دن جدول (^) وجود إرتباط دال إحصائياً عند مستوى ه . . بين التطبيقين الأول والثانى

لمقياس السعادة والتوجه نحو الحياة مما يثير إلى ثبات المقياس عند التطبيق.

ثانياً : مقياس المساندة الإجتماعية : ملحق (r)

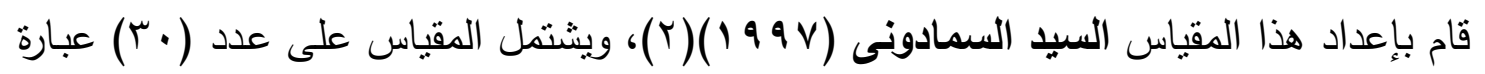

تعبر عن المساندة الإجتماعية لدى الفرد من الآخربن ، ويقوم الفرد بالإجابـة على المقياس وفقاً لدرجة انطباق الصفة عليه ، ويتم تصحيح المقياس في ضوء ميزان تقدير خماسى (تنطبق تماما ه درجات تتطبق كثيراً ع درجات - تتطبق أحيانا س درجات - تتطبق قليلاً درجتان - لا تتطبق على الإطـلاق

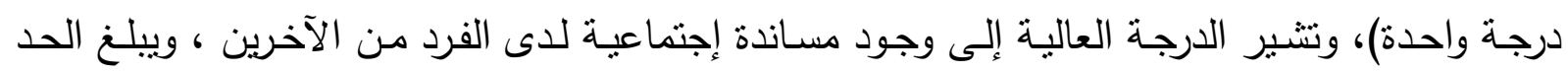
الأقصى لدرجات المقياس ( •0 1) درجة ، والحد الأدنى (•r) درجة.

وتشير الباحثة إلى أنه تم تعديل عبارتين من عبارات المقياس لتتاسب أفراد عينة البحث ، العبارة

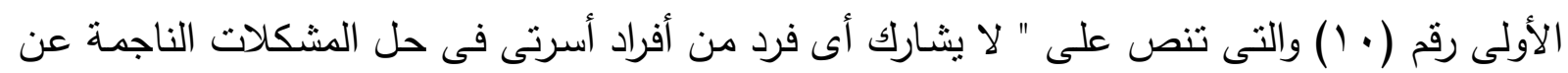
دراستى" ، تم تعديلها لتصبح " لا يشـارك أى فرد من أفراد أسرتى فى حل المشكلات الناجمة عن كبر سنى"، والعبارة الثانية رقم (·r) والتى تتص على "يزيل عنى أصدقائى حالة الهم والإنقباض الناشئة عن 
دراستى وحياتى ككل" ، تم تعديلها لتصبح "يزيل عنى أصدقائى حالة الهم والإنقباض الناشئة عن حياتى

قامت الباحثة بحساب معامل الصدق لمقياس المساندة الإجتماعيـة بإستخدام الصدق المنطقى، وذلك عن طريق عرض محتوى المقياس قيد البحث على عدد (0) من أساتذة علم الإجتماع والإجتماع لإعاع الرياضى (ملحق r) لإبداء الرأى فى مدى مطابقة ومنطقية عبارات المقياس لما وضعت من أجله ، وقد أظهرت النتائج إتفاق المحكمين بنسبة مئويـة قدرها ( . . . . \%) مما يثبر إلى توافر الصدق المنطقى للمقياس قيد البحث.

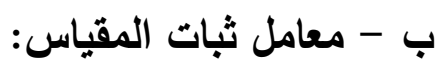

لحساب معامل الثبات قامت الباحثة بإستخدام طريقة تطبيق الإختبار ثم إعادته مرة أخرى، وذلك عن طريق تطبيق مقياس المساندة الإجتماعيـة على العينة الاستطلاعية وعددها (^) أفراد من مجتمع البحث وخارج العينـة الأساسية ، ثم إعادة التطبيق على نفس العينـة بفاصل زمنى قدره ( • ( ) أيام ، وتم حساب معامل الارتباط البسيط بين نتائج التطبيقين الأول والثانى ، وجدول (9) يوضح ذلك.

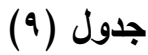

معامل الثبات لمقياس المساندة الإجتماعية قيد البحث

\begin{tabular}{|c|c|c|c|c|c|c|}
\hline \multirow{2}{*}{ قيمة "ر" } & \multicolumn{2}{|c|}{ التطبيق الثُاني } & \multicolumn{2}{|c|}{ التطبيق الأول } & \multirow{2}{*}{ القياس } & \multirow{2}{*}{ المقياس } \\
\hline & $\varepsilon$ & م & $\varepsilon$ & p & & \\
\hline$* \cdot . \vee \wedge r$ & $\varepsilon .7 Y$ & $9 \vee \ldots$ & $0 . . r$ & 97.Y. & لدرجة & المساندة الإجتماعية \\
\hline
\end{tabular}
يتضح من جدول (9) وجود إرتباط دال إحصائياً عند مستوى $ه$. . . بين التطبيقين الأول والثانى لمقياس المساندة الإجتماعية مما يشير إلى ثبات المقياس عند التطبيق.

ثالثاً : الأجهزة والأدوات المستخدمة فى البحث: - جهاز الرستامير لقياس الطول الكلى للجسم. - ميزان طبى معاير لقياس الوزن. - كرات قدم - طائرة - سلة - كرات يد. - ساعة إيقاف. - أقماع تدريب ملونة. - كرات جلد ملونة مقاسات مختلفة. 
1- تحسين الثـعور بالمسـاندة الإجتماعية والثـعور بالسعادة والتوجـه نحو الحباة للاى كبار السن من

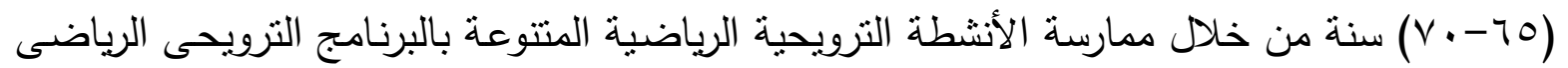

r- إيجاد روح المرح والسعادة بين أفراد عينة البحث الأساسية.

ب- إتاحة الفرصة للمسنين لممارسة نشاط ترويحى رياضى يتمشى مع قدراتهم البدنية والصحية. لتحقيق تلك الأهداف للبرنامج كان لابد وأن تتوافر فى البرنامج الترويحى الرياضى المقترح عدة شروط هى كما يلى : - أن يكون البرنامج شيق وجذاب ليمارسه المُسن بشكل يجلب عليه الثعور بالسعادة. - ألا تكون الأنشطة النترويحية الرياضية معقدة ولا نتسم بالتتوع. - إستخدام ألعاب ترويحية تربوية متتوعة تعمل على توطيد العلاقات الإنسانية والاجتماعية بين المسنين.

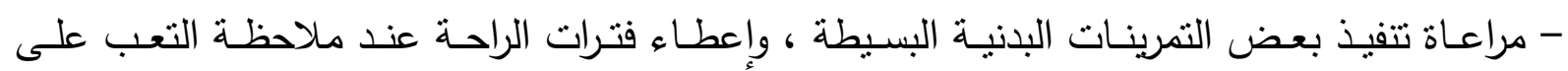

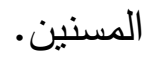

- مراعاة عامل الأمن والسلامة للمكان المخصص لتطبيق البرنامج والأدوات المستخدمة. وللتوصل إلى محتوى البرنامج الترويحى الرياضى المقترح قامت الباحثة بالإطلاع على المراجع

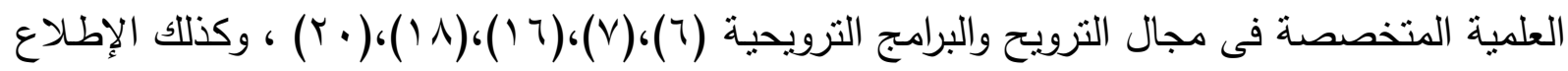

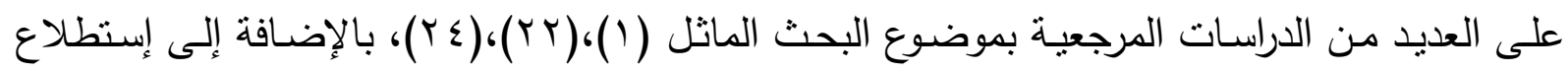

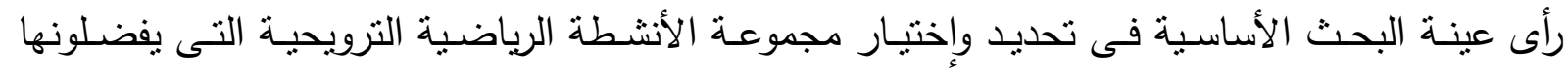
(ملحق \&) )، وبعد النوصل لمحتوى البرنامج تم عرضه على مجموعة من الخبراء فى مجال الترويح وعلم

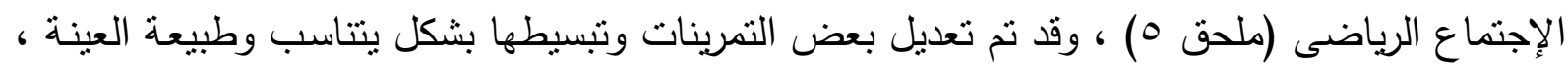
كما تم حذف بعض الأنثطة والتمرينات لصعوبتها. هذا وقد رأى الخبراء أن الفترة الزمنية المناسبة للبرنامج من الناحية الزمنية للوحدة الواحدة مدتها (0) (مقيقة ، وذللك لمدة (^) أسابيع متصلة. 
تم تقسيم الوحدة الترويحية اليومية إلى ثلاث أجزاء هى :

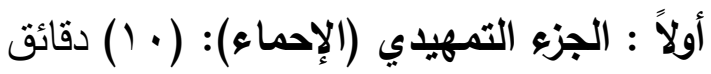

ويحتوى هذا الجزء على مجموعة من التمرينات البسيطة والمتتوعة مثل (المشى والجري والوثب)

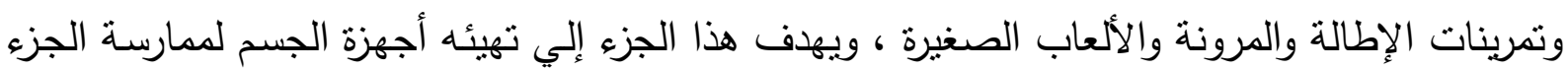
الرئيسى، وأستغرق تتفيذ هذا الجزء (• ( ) دقائق. ثانياً : الجزء الرئيسي: (0ب) دقيقة.

ويتضمن هذا الجزء على مجموعة من التمرينـات البدنيـة البسيطة ، وكذللك الأنشطة الرياضية

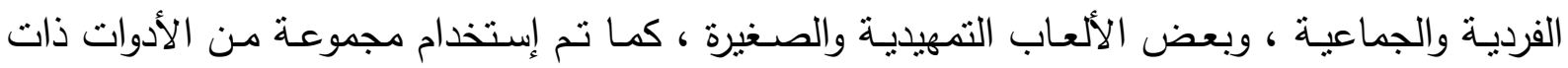

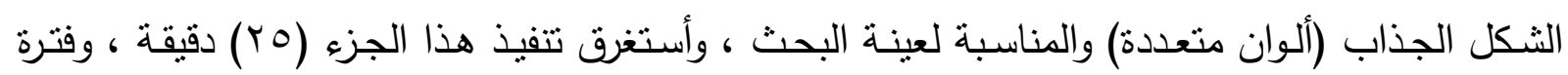

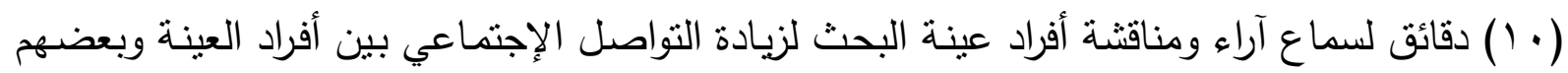

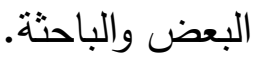

ثالثاً : الجزء الختامي : (0) دقائق ويحتوى هذا الجزء على بعض تمرينات التهيئة ، وأستغرق تتفيذ هذا الجزء (مق).

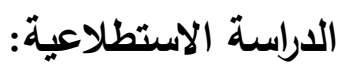

تم إجراء الدراسة الإسنطلاعية على أفراد العينة الإسنطلاعية وعددها (^) أفراد من مجتمع البحث

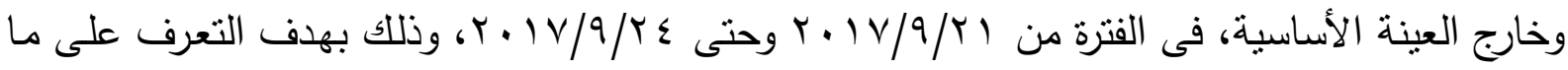
يلى : - مدى ملائمة محتوى البرنامج المقترح لأفراد عينة البحث. - مناسبة الأدوات المستخدمة وسهولة إستخدامها أثناء تطبيق البرنامج. - الصعوبات التى يمكن أن تلاقى الباحثة أثناء التطبيق.

وقد أظهرت نتائج الدراسة الإستطلاعية أن محتوى البرنامج الترويحى الرياضى صالح للنطبيق ،

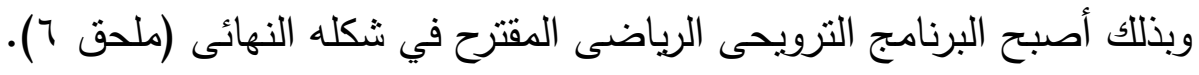


قامت الباحثنة بإجراء القياسـات القبلية لأفراد عينـة البحث الأساسية فى المساندة الإجتماعيـة

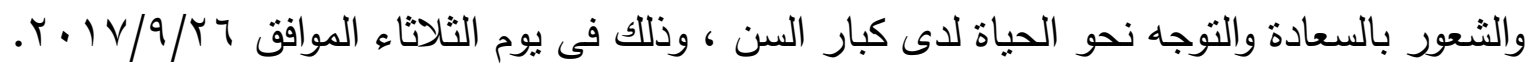
تطبيق البرنامج الترويحى الرياضى قيد البحث:

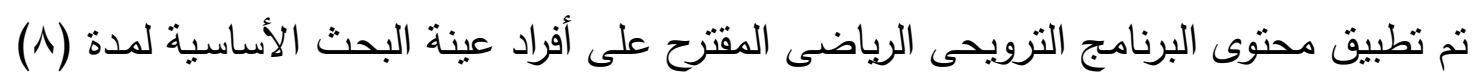

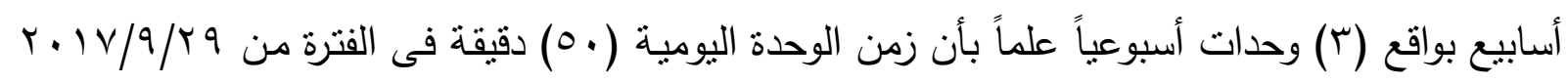

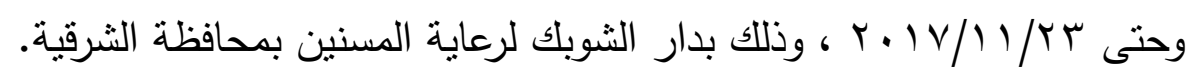

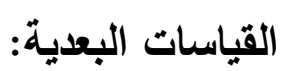

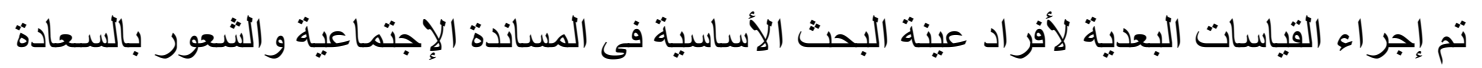

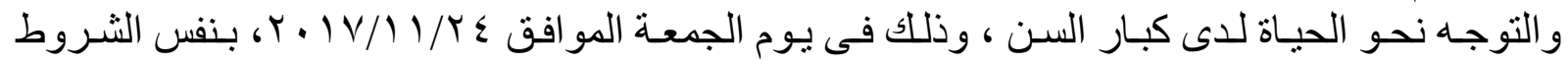
و الإجر اءات التى تم تطبيقها فى القياسات القبلية. الأساليب الإحصائية قيد البحث: أستخدمت الباحثة البرنامج الاحصائى (SPSS) ليُعالجة البيانات إحصائيًا ، وأستعانت بالأساليب

$$
\text { - م - معامل الإلتواء. }
$$

أولاً: عرض ومناقثة النتائج للفرض الأول للبحث والذى ينص على :" توجد فروق دالة إحصائياً بين

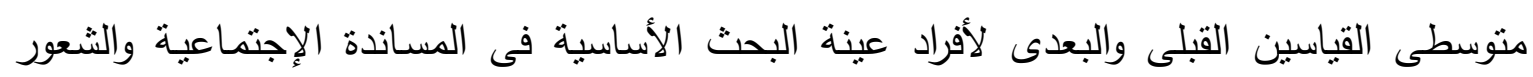
بالسعادة والتوجه نحو الحياة لصالح القياس البعدى".

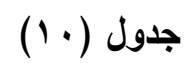

\begin{tabular}{|c|c|c|c|c|c|c|}
\hline \multirow{2}{*}{ قيمة ت } & \multicolumn{2}{|c|}{ القياس البعدى } & \multicolumn{2}{|c|}{ القياس القبلى } & \multirow{2}{*}{ القياس } & \multirow{2}{*}{ المتغيرات } \\
\hline & $\varepsilon$ & 5 & $\varepsilon$ & 5 & & \\
\hline *Y.9Y & 0.17 & $1 . \varepsilon . V$. & $0 . V r$ & 97.1. & لدرجة & المساندة الإجتماعية \\
\hline$* \varphi .01$ & $\{. \wedge 1$ & $\varepsilon \cdot$. & 0.17 & ro... & ل درجة & الشعور بالسعادة \\
\hline *Y.VI & $\varepsilon . \cdot r$ & $\leqslant 1 \ldots$ & $\varepsilon .01$ & rq.r. & درجة & التوجه نحو الحياة \\
\hline
\end{tabular}

دلالة الفروق بين القياسين القبلى والبعدى لأفراد عينة البحث الأساسية

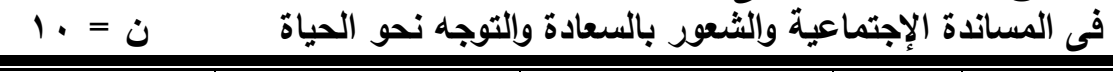

مجلة بحوث التربية الثاملة ـ كلية التربية الرياضية للبنات - جامعة الزقازيق - المجلد الأول ـ للنصف الأول للأبحاث العلمية ـ 1 1 بrم 
يتضح من جدول ( • () وجود فروق دالة إحصائياً عند مستوى ه . . بين القياسين القبلى والبعدى لأفراد عينة البحث الأساسية فى المساندة الإجتماعية والشعور بالسعادة والتوجه نحو الحياة لصالح القياس

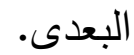

وترجع الباحثة التحسن فى المساندة الإجتماعية والثـعور بالسعادة والتوجه نحو الحياة لدى كبار

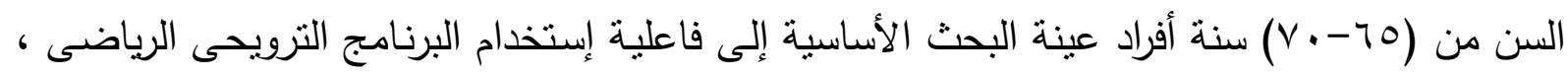
والذى أشنمل علي مجموعة من التمرينات البدنية البسيطة ، وكذلك الأنثطة الرياضية الفردية والجماعية ، وبعض الألعاب التمهيدية والصغيرة ، كما نم إستخدام مجموعة من الأدوات ذات الثكل الجذاب (ألوان متعددة) ، بالإضـافة إلى جلسات الحوار والإستماع للآخر والمناقثـات بين أفراد العينة والباحثة كل هذا أضفى جواً من البهجة والسرور على الوحدة ، حيث توفر الأنشطة الترويحية الرياضية ، وجلسات الحوار والمناقثات مجالاً خصباً للتنفيس عن الطاقات المكبوتة والضغوط النفية والإجتماعية سواء للزملاء أو المنافسين فالنشاط الترويحى الرياضى يوفر الفرص للتخلص من الضغوط النفسية والإجتماعية التى تقع على كاهل المسنين ، بالإضافة إلى أن ممارسة الأنشطة الترويحية الرياضية تعطى الفرصة لكل مسن أن يعبر عن مشاعره ، وأحاسيسه وتتمى قدراته وثقته بنفسه ، وتظهر مواهبه وتتمى معلوماته ، وتشعره أيضاً

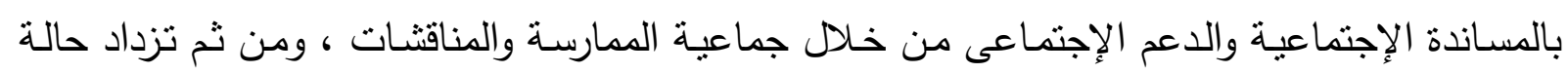
الثعور بالسعادة والتوجه نحو الحياة ، وتتفق هذه النتيجة مع ما أشنار إليه كل من : حلمى إبراهيم وليلى الإجى

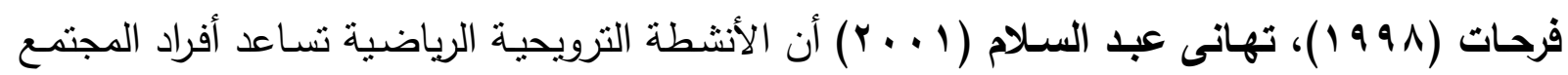
على إكتسـاب العـادات الإجتماعيـة المقبولة ، وتوجههم إلى كيفية حل المشكلات بطريقة تثتاسب مـع قدراتهم ، مما يكسبهم كثير من القيم المقبولة لدى مجتمعهم الذى يعيشون فيه ، كما أنها تؤدى إكساب الفرد السلوك الاجتماعى المطلوب ، كما تعمل على التخلص من الطاقة الزائدة لديهح ، والتى تسبب كثير من حالات الإكتئاب والقلق ، وبالتالى تتحسن حالة الشعور بالسعادة وجودة الحياة والإقبال عليها. $(1 \cdot \varepsilon: T) \cdot(Y Y V: V)$

كما تتقق هذه النتيجة مع نتائج دراسة كل من: وليد أمين عباس و إيمان رفعت السعيد

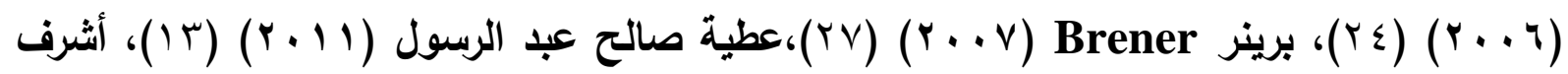

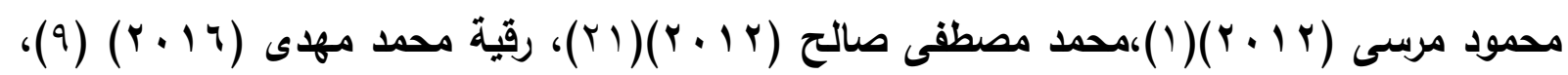

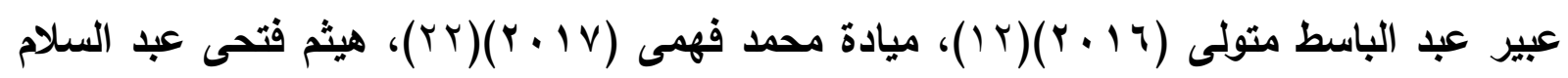

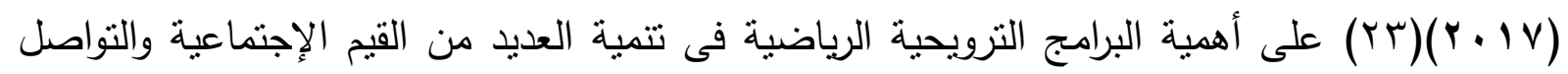
والتفاعل الإجتماعى بين ممارسى الأنشطة الترويحية الرياضية. 


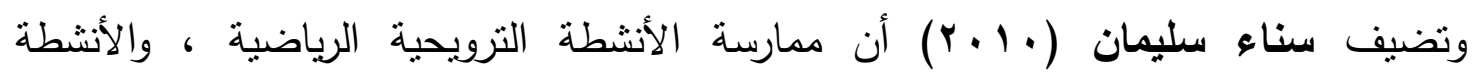

الإجتماعية تتمى لاى الفرد الصحة البدنية والنفسية والإجتماعية ، والقدرة على التفكير بطريقة واقعية ، فكلما شعر الأفراد بأنهم أصحاء وأفضل حالا، كلما أستمتعوا بحياة أفضل، بالإضافة إلى أنهم يكونون مفهوم ايجابي نحو الحياة.(1) (1:M (1)

\section{ويذلك يتحقى صحة الفرض الأول للبحث}

ثانياً : عرض ومناقثة النتائج للفرض الثانى للبحث والذى ينص على :" توجد نسب تحسن للقياس البعدى عن القبلى لأفراد عينة البحث الأساسية فى المساندة الإجتماعية والثعور بالسعادة والتوجه نحو الحياة ".

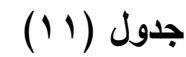

نسب تحسن القياس البعدى عن القبلى لأفراد عينة البحث الأساسية

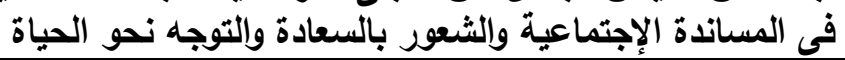

\begin{tabular}{|c|c|c|c|}
\hline \multirow{2}{*}{ ن = = نسب التحسن } & \multicolumn{2}{|c|}{ المجموعة الواحدة } & \multirow{2}{*}{ المتغيرات } \\
\hline & بعدى بع & قبلى & \\
\hline$\% \wedge .90$ & $1 . \varepsilon . v$. & 97.1. & المساندة الإجتماعية \\
\hline$\% 10 . v 1$ & $\varepsilon \cdot .0$ & ro... & الثعور بالسعادة \\
\hline$\% 1$ Y.90 & $\leqslant 1 \ldots$ & rq.r. & التوجه نحو الحياة \\
\hline
\end{tabular}

يتضح من جدول (1) توجد نسب تحسن للقياس البعدي عن القبلي لأفراد عينة البحث الأساسية

فى المساندة الإجتماعية والشعور بالسعادة والتوجه نحو الحياة قيد البحث.

وترجع الباحثة هذا التحسن فى المساندة الإجتماعية والثعور بالسعادة والتوجه نحو الحياة لدى

أفراد عينة البحث الأساسية إلى فاعلية البرنامج الترويحى الرياضى والذى تضمن الأنشطة الرياضية والترويحية والإجتماعية والتواصل الإجتماعى بين الأفراد فجعل كبار السن يشعرون بالدعم الإجتماعى من الزملاء والآخرين فخلق جو مريح للمسن يستطيع من خلاله تفريغ كل ضغوطه ومشاكله النفسية والإجتماعية فكان المردود الشعور بالسعادة من جو الألفة والتعاون، ومن ثم تغيرت وجهة نظر المسن نحو الحياة.

تتفق هذه النتيجة مع ما أثنار إليه كل من : برينر Brener (999 ( ))، جايلى كسينج

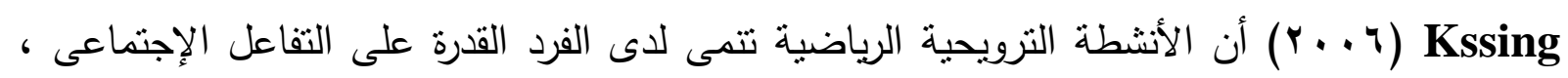
ومهارات الإتصال الجيد مع المحيطين به ، كما أنها تخلق جو من السعادة والسرور ، والتوجه الإيجابى

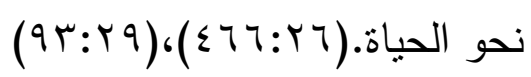




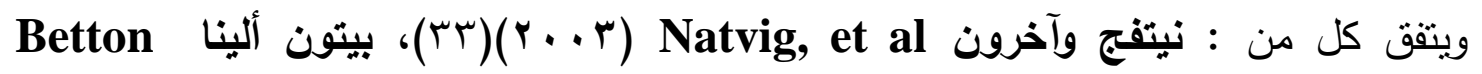
(Y) Alena والتوجه نحو الحياة ، وتقدير الذات لدى الأفراد ، ومن أوجه المساندة الإجتماعية مزاولة الأنشطة

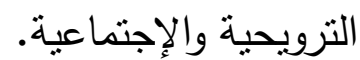

\section{ويذلك يتحقق صحة الفرض الثانى للبحث}

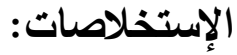

فى حدود أهداف وفروض البحث والنتائج التى توصلت إليها الباحثة تم إستخلاص ما يلى:

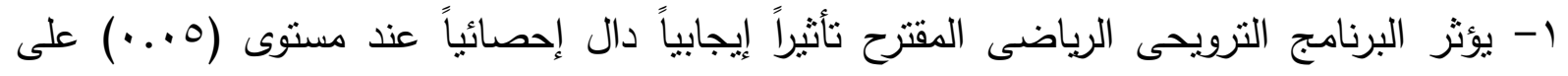
المساندة الإجتماعية لدى كبار السن من (10 - • V) سنة بدور الرعاية بمحافظة الثرقية.

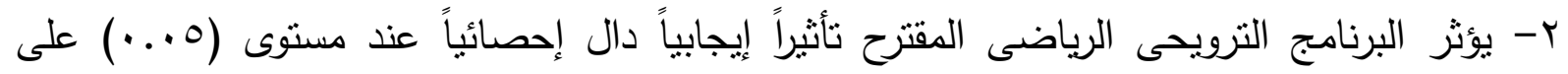

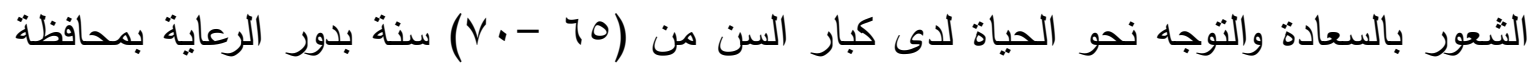

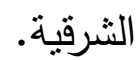

r- توجد نسبة تحسن للقياس البعدي عن القبلي لأفراد عينة البحث الأساسية فى المساندة الإجتماعية بلغ

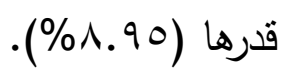
ع - توجد نسبة تحسن للقياس البعدي عن القبلي لأفراد عينة البحث الأساسية فى الثعور بالسعادة بلغ

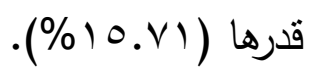
ه- توجد نسبة تحسن للقياس البعدي عن القبلي لأفراد عينة البحث الأساسية فى التوجه نحو الحياة بلغ

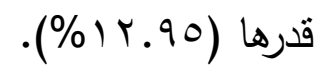

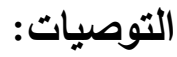
فى ضوء نتائج البحث توصى الباحثة بما يلى : 1- إستخدام البرنامج الترويحى الرياضى المقترح لما له من نأثثر فعال فى تحسين الثعور بالمساندة

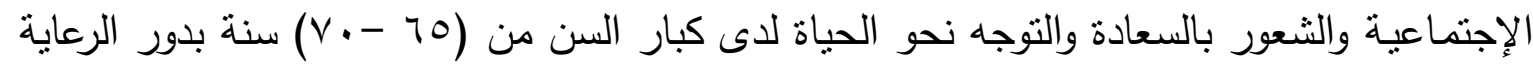
الإجتماعية بمحافظة الثرقية.

r- الكثف المبكر عن مستوى المساندة الإجتماعية والثعور بالسعادة والتوجه نحو الحياة لاى كبار

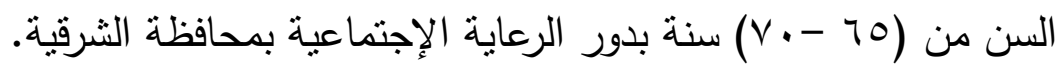


- $\leqslant$ -

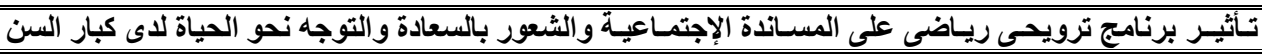

r- تفعيل دور البرامج الترويحية الرياضية فى تحسين قيم التواصل الإجتماعى والحد من حالة القلق والإكتئاب لدى كبار السن من (0 - • V) سنة بدور الرعاية الإجتماعية بمحافظة الشرقية.

ع - عقد دورات تدربيية للأخصائيين الإجتماعيين للتدربب على كيفية وضع وتتفيذ البرامج الترويحية الرياضية لدى كبار السن بدور الرعاية الإجتماعية.

- إستخدام المقاييس قيد البحث للوقوف على حالة المساندة الإجتماعية والثعور بالسعادة والتوجه نحو الحياة لدى كبار السن من (07 - • V) سنة بدور الرعاية الإجتماعية. 
$-\varepsilon r r_{-}$

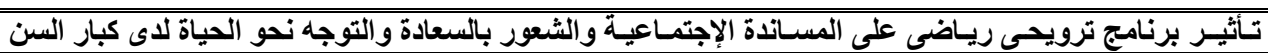

المراجع

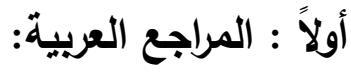

ا - أشرف محمود مرسى (Y Y Y Y):" تأثنير برنامج ترويحى رياضى مائى على بعض المتغيرات النفسية لدى كبار السن"، مجلة بحوث التربية الرياضية ، المجلد (جء) ، العدد (^^) ، كلية التربية الرياضية بنين ، جامعة الزقازيق.

ץ- السـيد السـمادونى (9 9 V ( )): مقياس المسـاندة الإجتماعيـة - كراسـة التعليمـات والثـرط ، مكتبـة الأنجلو المصرية ، القاهرة.

ب- أمطانيوس ميخائيل ( • ( • r):" مؤشرات الثبات والصدق لمقياس الرضا عن الحياة المتعدد الأبعاد للطلبة على عينات سوربة"، مجلة العلوم التربوبة والنفسية ، المجلد الحادي عشر ، العدد

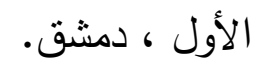

ع - أمل أنور عبد العزيز ، عبد الرحيم نجيب عبد الرحيم (999 99 ):" السلوك التقبلى لدى عينة من المسنين"، بحوث المؤتمر الدولى للمسنين، مركز الإرشاد النفسى، جامعة عين شمس.

ه - بشرى إسماعيل (ع ا • ؟): المساندة الاجتماعية والتواقق المهني ، مكتبة الأنجلو المصرية، القاهرة. צ - تهانى عبد السلام محمد (1 ץ): الترويح والتربية الترويحية ، دار الفكر العربى ، القاهرة.

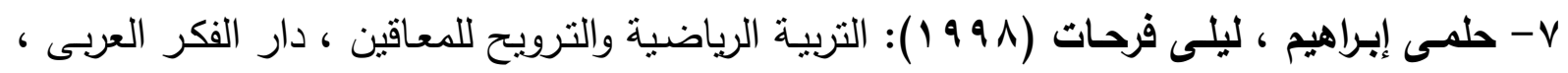
القاهرة.

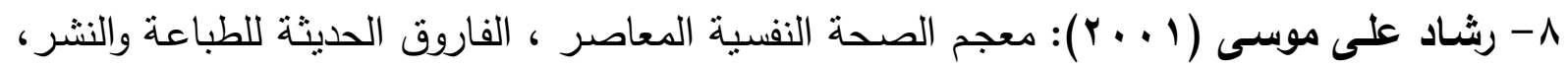
القاهرة.

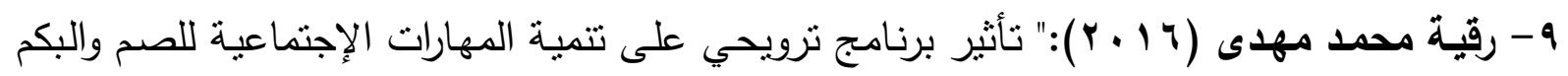
بمحافظة المنوفية" ، رسالة دكتوراه ، كلية التربية الرياضية ، جامعة مدينة السادات.

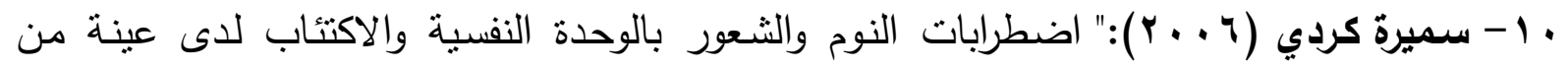
المسنات في مدينة الطائف"، مجلة كلية التربية ، العدد الثلاثثن ، الجزء الأول.

1 - سناء سليمان ( • ( • ): السعادة والرضا أمنية غالية وصناعة راقية ، عالم الكتب للنشر ، ، القاهرة. 
r ا - عبيز عبد الباسط متولى (T 1 ـ ץ):" فاعلية برنامج ترويحي باستخدام الألعاب الصغيرة والتمهيدية على تتمية بعض المهارات الأساسية والتفاعل الإجتماعى للناشئين فى كرة السلة"، رسالة

دكتوراه ، كلية التربية الرياضية بنات ، جامعة الزقازيق.

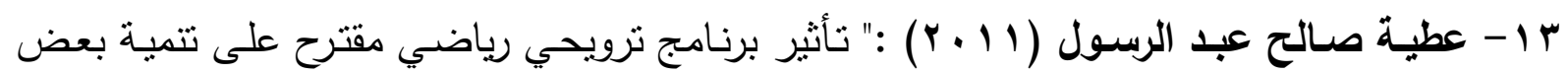
عناصر اللياقة البدنية والخصائص الإجتماعية للنلاميذ المعاقين سمعياً بشعبية بنغازى"، رسالة ماجستير ، كلية علوم التربية البدنية والرياضة ، جامعة الفاتح ، ليبيا.

ـ ا - فهمي علي ( • 1 ـ ץ):" التوجه الإيجابي نحو الحياة وعلاقته ببعض سمات الثخصية السوية لدى عينة من طلاب الجامعة من الجنسين" ، المؤتمر الإقليمي الثاني لعلم النفس، رابطة الأخصائيين النفسبين المصربة ، القاهرة.

ه - فؤاد أبو حطب ، آمال صـادق (^ ، . ץ) : نمو الإنسان من مرحلة الجنين إلى مرحلة المسنين ، طس ، مكتبة الانجلو المصرية ، القاهرة. 7 1 - كمال درويش ، محمد الحماحمى (9 9V ( )): رؤية عصرية للتروبح وأوقات الفراغ، مركز الكتاب للنشر ، القاهرة.

V ا - مايسة النيال ، ماجدة على (909 9 ( )):" السعادة وعلاقتها ببعض المتغيرات النفسية والثخصية لدى عينة من المسنين والمسنات، مجلة علم النفس، العدد(بr) ، الهيئة المصرية العامة للكتاب، القاهرة.

1 ا - محمد السمنودي (r + . r): التروبح الرباضي وأوقات الفراغ ، مكتبة شجرة الدر ، المنصورة. 9 ا - محمد محروس الثـناوى ، محمد السيل عبد الرحمن (10 + ب): المسـاندة الاجتماعية والصحة النفسية - مراجعة نظرية ودراسات تطبيقية ، طץ، الأنجلو المصرية ، القاهرة.

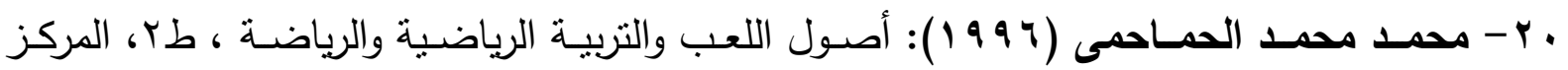
العربى للنشر والتوزيع ، القاهرة.

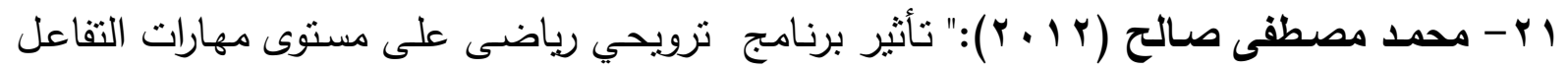
الإجتماعى لدى الأطفال التوحديين"، رسالة ماجستير ، كلية التربية الرياضية ، جامعة 
تأتثـر برنامج ترويحى ريـاضى على المسـاندة الإجتمـاعيـة و الثُعور بالسعادة و التّوجه نحو الحياة لاى كبار السن

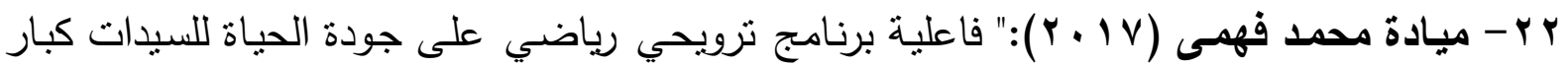
السن"، رسالة ماجستير ، كلية التربية الرياضية ، جامعة المنصورة.

r r - هيثم فتحى عبدالسـلام ( IV r):" برنامج ترويحي مائى لخفض السلوك النمطى وتتمية التفاعل الإجنماعى لاى أطفال التوحد"، رسالة ماجستير ، كلية التربية الرياضية ، جامعة بنها.

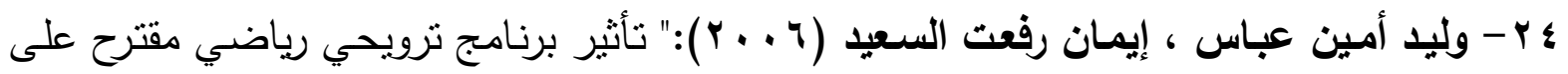
الحالة النفسية والاجتماعية لكبار السن فوق سن 10 سنة"، مجلة العلوم البدنية والرياضية ، العدد (9) ، كلية التربية الرياضية ، جامعة المنوفية.

ثانياً: المراجع الأجنبية :

25-Betton Alena (2004): Psychological Well-being and spirituality among African American and European American college students, A dissertation presented in partional fulfillment of the requirements for the degree doctoral of philosophy in the graduate school of the Ohio state university.

26-Brener, M., (1999): Aqualitaive examination of the effects of family violence on children's educational experience, Journal of Applied Psychology, Vol.,116, No.,3,

27-Brener,M., (2007): effect sporting activities on the vital organs and mental elderly, Journal of Medical Science, Vol., 5,No., (1).

28-Cohen, S., \& Wills, T., (1985): Stress ,social support, and the buffering hypothesis, Psychological Bulletin, Vol., 98,,pp.,310-357.

29-Gayle Kssing (2006):Into duction to recleation and ieiuize,con guer,Cataloging Publication data, Human Kinetice.

30-Joseph, et., al, (2004) :" Rabid assessment of wellbeing: the short depression- happiness scale " psychology \& psychotherapy: theory, Research \& practice, Vol., 77, No.,4 , pp. $463-478$.

31-Lepore, S., (1994) : Social support . Encyclopedia of Human Behavior, Vol.,4, pp., 247-251. 
32-Mook, J. , Klieijn, W. , \& Ploeg, H., (2005): Positively and negatively worded items in a self - reported measure of dispositional optimism, Psychological Reports, No., 71, pp., $275-278$.

33-Natvig, G., Albrektsen, G., \& Qvarnstrom, U., (2003):"Association between psychosocial factors and happiness among school adolescents", International Journal of Nursing Practice. Vol., 9, No., (3), pp., 166-175.

34-Sarason,L., et.,al.,(1983):Assessing social support: The social support questionnaire, Journal of Personality and Social Psychology ,Vol. 44, No.1, pp.,127-139.

35-Skarbon,M., \& Nicki,R., (2010):Worry in per and post retirement persons, International, Journal of Aging and human Development,Vol.,50, No.,1, pp., 61-71.

36-Von Bonsdorff,et.,al (2009):"The Choice between Retirement and Bridge Employment: A Continuity Theory and Life Course Perspective International Journal of Aging and Human Development, vol.69, no.2, pp.,79-100. 